\title{
MEDIAÇÃO E AFETIVIDADE NO TDAH: REFLEXÕES NECESSÁRIAS
}

\author{
MEDIATION AND AFFECTIVENESS IN ADHD: NECESSARY REFLECTIONS
}

\section{Eliane Holzlechner Taube}

Rede Municipal de Educação de Ijuí, Ijuí, RS, Brasil. E-mail: elianeht@hotmail.com

DOI: https://doi.org/10.46550/amormundi.v2i5.119

Recebido em: 14.07.2021

Aceito em: 10.09.2021

\begin{abstract}
Resumo: A presente pesquisa tem como objetivo descobrir e identificar a importância da mediação e da afetividade de um professor no processo de ensino de alunos com TDAH. Caracterizando que este processo pode auxiliar no processo de aprendizagem, na intervenção e atendimento aos alunos que apresentam o referido transtorno, já que o transtorno de déficit de atenção/hiperatividade - TDAH traz uma grande falta de compreensão e efeito na rotina da escola e na vida das pessoas. Trata-se de uma pesquisa que foca no processo de mediaçáo e afetividade, fundamentada por pensadores que entendem o desenvolvimento humano em uma dimensão sócio histórica. Observando que apesar da experiência dos docentes com os alunos com TDAH, ainda se peca na falta de reflexão e saberes que oportunizam de fato o ensino e aprendizagem do referido aluno. Evidenciando assim a real importância do professor afetivo como mediador, superando limites e dificuldades que os alunos passam.
\end{abstract}

Palavras-chave: Afetividade. Mediação. Aprendizagem.

Abstract: This research aims to discover and identify the importance of mediation and affectivity of a teacher in the teaching process of students with ADHD. Characterizing that this process can help in the learning process, in the intervention and care of students with the aforementioned disorder, as attention deficit/hyperactivity disorder - ADHD brings a great lack of understanding and effect on school routine and life of people. It is a research that focuses on the process of mediation and affectivity, based on thinkers who understand human development in a socio-historical dimension. Noting that despite the experience of teachers with students with $A D H D$, there is still a lack of reflection and knowledge that actually provide opportunities for teaching and learning of that student. Thus, showing the real importance of the affective teacher as a mediator, overcoming limits and difficulties that students go through.

Keywords: Affection. Mediation. Learning. 


\section{Introduçáo}

Presente trabalho visa investigar a importância da mediação e da afetividade no TDAH, aborda e enfatiza de como ele acontece na relação dos envolvidos e quais os seus benefícios para o desenvolvimento na aprendizagem. Apesar de muitos saberes e mesmo com inúmeros exemplos se voltarem para a importância da mediação com afetividade, ainda continua sendo um tema bem difícil e bem amplo para ser estudado.

O TDAH é muito mais que um diagnóstico, é compreender, é aceitar, é dar carinho, é dar afeto, é trabalhar juntos é encontrar o melhor caminho para alcançar os melhores objetivos.

O educador do TDAH precisa compreender que um futuro está em suas mãos e que suas mãos podem direcionar o futuro de uma criança, que muitas vezes só está implorando um carinho e um afeto. Mediar com afetividade e o bem mais precioso que o ser humano possui para dar ao seu aluno, pois só assim conseguirá deixar as suas lembranças em um pequeno ser.

\section{Transtorno de Déficit de Atenção e Hiperatividade: contexto histórico e definiçóes}

O presente trabalho vem ao encontro de uma melhor amplitude, de um melhor entendimento na busca de respostas que fluem em pensamento. Buscar orientaçóes para entender e auxiliar alunos muito agitados, é que surge a curiosidade e a busca de informaçóes para procurar desenvolver a melhor maneira de efetuar o processo de ensino e aprendizagem.

Minha motivação perante a este assunto é ampliar os conhecimentos para possibilitar uma melhor mediação na atuação como psicopedagoga, conhecer melhor esta dificuldade que paira em muitas escolas, que está presente, e muitas vezes não diagnosticado como sendo um transtorno do TDAH.

O objetivo geral é investigar qual a contribuição da afetividade na intervenção psicopedagógico, e de como os fatores afetivos interferem na intervenção do educador com o seu aluno, influenciando, desta forma na aprendizagem.

Através desta curiosidade, através da vontade de mediação neste processo é que surge a ideia de um estudo mais aprofundado sobre o TDAH. Entender um pouco mais sobre este transtorno que muitas vezes por falta de informaçóes, é desconhecido ou desleixado pelos profissionais da educação, confundido com uma má - educação, " má - criação" ou a " falta de limites”, gerando consequências graves em seu desenvolvimento no processo de ensino e aprendizagem.

O TDAH é representado por sintomas de desatenção de hiperatividade ou impulsividade, podendo ser classificado em três subtipos: $\mathrm{O}$ primeiro apresenta a desatenção, sendo aquelas crianças com uma grande dificuldade de manter o foco, são desorganizadas e se distraem facilmente. $\mathrm{O}$ segundo subtipo apresenta a hiperatividade/impulsiva que são aquelas que não param quietas e que se remexem muito, embora possuem menos dificuldade escolar, mas por outro lado acabam sendo mais agressivas sofrendo uma grande rejeiçáo. O último subtipo é o que chamamos de combinados trazendo os critérios de desatenção hiperatividade e impulsividade.

Longe de ser uma doença o TDAH apresenta ser um funcionamento mental acelerada, agitado, de uma forma inteligente ou de uma forma desnorteada, a criança com este transtorno primeiro faz para depois agir. 
O Transtorno de Déficit de Atenção e Hiperatividade é um distúrbio genético neurológico, caracterizado pelos sintomas de desatenção acentuada, hiperagitação motora e excessiva impulsividade, bastante presente na vida acadêmica. Aparece na infância e na maioria das vezes segue por toda a vida, sendo que em, cerca de $70 \%$ do transtorno segue na vida adulta, ressaltando que não é uma doença, por isso não existe cura, mas sim um tratamento para melhor conviver com ele. Mesmo aparecendo na infância, o diagnostico pode ficar mais visível no momento em que a criança vai para uma escola, pelas alteraçóes e comportamentos apresentados ali, apresentando uma dificuldade de prestar atenção, de ficar parado e até uma dificuldade de brincar com outras crianças.

Rohde e Mattos (2003) consideram também a relação de fatores ambientais e agentes psicossociais como desajustes familiares, criminalidade, psicopatologia materna e o uso de substâncias como o álcool e a nicotina durante a gestaçáo, como possíveis agentes desencadeadores do TDAH. Os autores também observam que na idade escolar o sintoma tem maior prevalência em meninos na infância, na adolescência há um equilíbrio entre os sexos e nos adultos jovens ocorre um predomínio feminino. Foi observado também que no sexo feminino há um predomínio de desatenção, enquanto no homem são expressivas a hiperatividade e a impulsividade, entretanto há variações.

Sendo que para Barkley (2002) o problema central do transtorno não pode ser compreendido apenas como falta de atenção e hiperatividade, mas segundo o autor a questão fundamental está na incapacidade de inibir tais comportamentos. A diferença de uma criança com TDAH e da outra é a intensidade e a frequência que acontece as três principais características. Tudo nela é a mais e quase nunca passa desapercebida mesmo estando discretamente vestida.

De acordo com Vigotski (2004), a aprendizagem é um processo social, sendo que, podemos afirmar que o desenvolvimento da criança na escola tem uma grande importância, ajudando a criança a alcançar a plenitude de seu desenvolvimento e seu potencial. Vigotski (2004 também destaca a importância do brincar para os processos de aprendizagem e desenvolvimentos da criança, pois é através dessas experimentaçôes e vivencias que se percebe o mundo exterior.

As crianças com dificuldade de aprendizagem não são crianças incapazes de aprender, ao contrário disso são crianças que possuem um nível de inteligência muito bom, apenas possuem uma dificuldade de aprender pelo fato de sua desatenção.

A criança com o TDAH tem toda plenitude para desenvolver seu potencial, mas quando não é compreendida passa a ter um baixo desempenho e uma visão errada de si mesma, sendo sua vida um verdadeiro abismo. Porém, quando perde a atenção, deixa seus projetos de lado, deixando assim de concluir seu desenvolvimento. Salientando que é fundamental e de suma importância o papel do educador, cujo estímulo constante é a única ferramenta capaz de proporcionar a plenitude das vivências e experimentaçôes, garantindo assim um maior aproveitamento.

Crianças hiperativas são aquelas que não conseguem prestar atenção em nada, correm, pulam, sobem e caem, apresentando - se sempre a mil. Estas crianças possuem uma grande dificuldade de aprendizagem e de relacionamento com os outros, deixando assim uma sala de aula em uma verdadeira batalha. Possuem uma grande dificuldade de se expressar, isto ocorre pela velocidade com que seu cérebro processa os pensamentos, e outro problema da comunicação é o desempenho de sua autoestima, do qual já no início da vida infantil pode ser muitas vezes mal interpretada, sendo rotuladas como, cabeça de vento, pestinhas, monstrinhos, destruidores 
e rebeldes, comportamentos estes característicos de um TDAH.

Desta maneira o aluno com TDAH possui grandes dificuldades no aprendizado escolar e por consequência um mau rendimento, vivenciando fatores de incompreensão do grupo, causando lhe uma baixa autoestima, o que acaba causando infelicidade e frustação, tornando a escola uma verdadeira "tortura” para a criança que acabará desenvolvendo uma atuação antissocial e comportamentos destrutivos.

Se observa e se torna cada vez mais comum o déficit de atenção das crianças nas escolas, e uma das questôes influenciadora neste processo é e tem sido a questão familiar, a afetividade familiar deve ser o primeiro suporte para a sua vida, as crianças não conseguem entender os conflitos familiares e acabam sendo atingidas transmitindo isto para o seu desenvolvimento escolar.

Outro aspecto influenciador é de os professores não serem afetivos e não compreenderem que seus alunos não aprendam por causa de alguma dificuldade em seu aprendizado ou por terem problemas familiares. Nossas crianças necessitam deste lado afetivo, pois quando o ambiente é seguro, as crianças se sentem afetivamente seguras, facilitando até a escola a conseguirá lidar com estes problemas, pois a afetividade está ligada em todas as esferas do ser humano ajudando em todos os aspectos de seu desenvolvimento.

\section{A mediaçáo com afetividade}

Não se pode esquecer que os seres humanos são seres emotivos e trazem consigo marcas profundas desde a gestação, que muitas vezes são ignorados pelos professores pela função do cumprimento de tempo determinado para certo conteúdo. A afetividade passa por todo o processo educacional e muitas vezes se preocupa tanto com o que se quer passar e acaba esquecendo do mais importante, o diálogo e o laço afetivo de ambos, laços estes táo profundos que serão eternos,

Quando a família e a escola trabalham juntas com a criança com TDAH, juntas podem auxiliar no seu tratamento e na sua socialização, não se esquecendo, que impor limites é necessário, pois se vive numa sociedade cheia de regras e limites. Verifica - se que quando há afeto da família e da escola na qual a criança se sente segura e amparada, seu desenvolvimento se torna mais fácil e mais digno. A afetividade no processo de ensino e aprendizagem fará com que a criança consiga se interagir com seus colegas e também com a professora.

Alguns professores dão esta oportunidade aos seus alunos, mas outros não, por terem receio da mudança que afetividade pode causar. Muitas vezes os alunos buscam esta atenção e compreensão, porém não estão sendo compreendidos e aceitos.

Segundo Cury, em seu livro Pais Brilhantes e Professores Fascinantes (2003 p. 64), cita que o "hábito dos professores fascinantes contribui para o desenvolver: auto estima, estabilidade, tranquilidade, capacidade de contemplação do belo de perdoar, de fazer amigos, de socializar". Deixando claro que a afetividade conduz todo o processo de interaçáo despertando sentimentos prazerosos, não permitindo que atitudes agressivas afetam seu equilíbrio emocional.

Uma das grandes diferenças no processo de ensino e aprendizagem do aluno com TDAH com certeza é afetividade, pois acima de qualquer outro método a afetividade pode ser o ponto essencial neste processo, pois é através dela que o professor conseguirá chegar até o seu aluno e 
desenvolver o seu potencial. O aluno precisa se sentir seguro, compreendido e respeitado pelo professor, para que ele se sinta seguro e possa se desenvolver de uma melhor maneira atingindo assim a plenitude.

A afetividade vai determinar o tipo de relação que irá existir entre o professor e o aluno, é ela quem dará um grande impacto de como o aluno vai adquirir o seu conhecimento. Transmitindo afetividade a criança entenderá quando será cobrada, saberá quando pode chegar até o seu professor para um aconchego, para um carinho, para um abraço e uma boa comunicação, cultivando um laço confiante entre os dois. Wallon (2007) mostra que afetividade é expressada de três maneiras: pela emoção, pelo sentimento e pela paixão os quais surgem ao longo de sua vida.

A emoção é a primeira expressão da afetividade não sendo controlada pela razão. $O$ sentimento possui um caráter mais cognitivo e representa a sensação do momento. Já a paixão possui a característica do autocontrole e se manifesta quando o indivíduo domina o medo. Salientando que a emoção é a forma mais expressiva da afetividade, sendo impossível falar de afetividade sem ter emoçóes.

A relação entre as dimensóes, motora, afetiva e cognitiva é considerada o conceito central da teoria de Wallon a qual é claramente descrita por Mahoney (2000, p. 15).

O motor, o afetivo, o cognitivo, a pessoa embora cada um desses aspectos tenha idade estrutural e funcional diferenciada, estâo tão intrigados que cada um é parte constitutiva do outro. Sua separação se faz necessária apenas para a descrição do processo. Uma das consequências dessa interpretação é de que qualquer atividade humana sempre interfere em todos eles. Qualquer atividade motora tem ressonância afetiva e cognitiva, toda disposição afetiva tem ressonância motora e cognitiva, e toda operação mental tem ressonância afetiva e motora. E todas essas ressonâncias tem um impacto no quarto conjunto: a pessoa.

Para ajudar uma criança com TDAH o primeiro passo é estudar muito sobre o assunto, buscar informaçôes para poder enxergar melhor o mundo através do olhar desta criança. $\mathrm{O}$ segundo passo é saber diferenciar a desobediência da inabilidade.

A criança na escola como aponta Saltini (2008), deseja e necessita ser amada, aceita, acolhida e ouvida para que possa despertar para a vida da curiosidade e aprendizado. Confiança e segurança do aluno para com o professor são fundamentais que levam a desenvolver várias habilidades como por exemplo, trocar experiências e se expressar.

Compreendemos que não existe uma solução simples e mágica para os alunos com TDAH, mas sim tempo, dedicação, afeto e persistência. Como dizia o poeta Carlos Drumond de Andrade: "Amar se aprende amando".

\section{Segundo Solé:}

Dizer que ensinar é difícil, que o professor tem diante de si uma complexa e árdua tarefa, que não se restringe apenas aos aspectos formativos no âmbito da sala de aula, mas que inclui aspectos formativos no âmbito da sala de aula, mas que inclui aspectos de gestáo e de manejo de relaçóes humanas no contexto da escola, seria arriscar que venham a nos considerar, no mínimo, pouco originais. Muito bem: corremos este risco. Porque só a partir de uma breve analise daquilo que essa complexidade envolve, das questóes que coloca e dos requisitos a serem observados pelas respostas que exige, parece - nos possíveis oferecer uma visão ajustada daquilo que cabe esperar de um referencial explicativo dos processos de 
ensino e aprendizagem. (SOLÉ, 1998, p. 9).

Para melhorar e garantir um aproveitamento escolar satisfatório, o colégio e a família precisam andar juntas em estrema sintonia, é fundamental que a criança com TDAH sinta -se bem, num ambiente receptivo e aberto as diferenças e aos ritmos da aprendizagem. Lembre-se da parte emocional do aprendizado. Estas crianças necessitam de um apoio especial para encontrar prazer na sala de aula. Domínio ao invés de falhas e frustaçôes.

Jamais se deve esquecer de que, para a criança com TDAH, elogios, incentivos e demonstraçôes de amor são essencialmente eficaz ao um bom comportamento, mantendo esta repetição a criança tornará comum os comportamentos adequados não precisando mais ser recompensada. O objetivo principal é abandonar a valorização das atitudes negativas das crianças fazendo com que ela perceba que chama mais atençáo quando faz algo de errado, para uma maneira de sempre incentivar, reforçar e promover o sucesso dela, dando mais atenção aos bons momentos.

A criança com TDAH prevê sua consequência em seu comportamento impulsivo, mas possui uma muita dificuldade muito grande em conte -lo. Esta criança é fortemente repreendida, já por outro lado quando acerta não recebe elogios, deixando assim uma confusão na cabeça dela, achando que tudo que ela faz é errado e nada certo. Ao dar uma ordem negativa é provável que a criança obedeça a esta ordem, até que se distrai e comete o mesmo erro novamente, sendo repreendida por várias vezes causando um clima desagradável para todos. Por outo lado podemos colocar como ordem positiva, serena e náo ameaçadora, instruindo de como fazer o certo, lembrando que logo deverá ser recompensada pela sua atitude.

Mostre sempre que você a ama e quanto fica feliz por cada atitude que ela consegue fazer, recuperando sua autoconfiança cada vez mais. Dentro os vários fatores que afetam positivamente o desempenho de um aluno com TDAH está a estruturação da sala de aula e durante o tempo de estudo em casa. Uma sala bem estruturada não é uma sala rígida, mas sim criativa, ativa e estimulante.

Segundo Rossini (2001, pp. 15-16) a proposta pedagógica afetiva significa que

As crianças devem ter oportunidades de desenvolver sua afetividade. É preciso dar lhes condiçôes para estar ligado ao ato afetivo, deve ser gostoso, prazeroso, que seu emocional floresça, se expanda, ganhe espaço. A falta de afetividade leva à rejeição aos livros, a carência de motivação para aprendizagem, a ausência de vontade de crescer.

É preciso criar oportunidades para que isto aconteça, direcionando brincadeiras que levam e oportunizam a interação deste sentimento, é preciso mostrar a importância de cada um naquele local e de quão prazeroso é sua presença independente do seu modo de ser.

Segundo Zuchi (2006) apud por Lima e Souza (1984, p. 9), "a afetividade compreende o estado de ânimo ou humor, os sentimentos, emoçôes e as paixôes, ou seja, a capacidade de experimentar, vivencias, sentimentos e emoções".

$\mathrm{Na}$ educação o estudo da afetividade é bastante recente. O legado filosófico deixado nesta área dificulta a introdução deste tema, posto como não relevante, marginalizado e generalizado, rompendo as barreiras da vida escolar. Só a partir da década de 70 temos o surgimento de estudos que passam a incluir a variável mais subjetiva como a afetividade. 
Ressalta Wallon (1971), que é preciso compreender que por trás da descarga impulsiva existe a expressão das necessidades múltiplas da criança que reclama de afeto, ajuda e compreensão. A afetividade e a determinação confirmam uma grande importância ao campo psicoemocional da criança hiperativa. $\mathrm{O}$ afeto revela uma intensa sensibilidade e reatividade emocional a um modo generoso de ser com o outro. Os mediadores precisam ter mais paciência e compreensão com os alunos que possuem ou apresentam este comprometimento, ser receptivo para conseguir lidar com estas dificuldades, conversar mais e tentar entender suas dificuldades e ouvir seus problemas, pois a atenção é o que eles mais querem e pedem.

Com a era da tecnologia, que aproxima as pessoas através do contato, mas afasta e as impedem de terem um laço afetivo, olho no olho, um abraço e as troca de experiências em uma roda de conversa, muitas vezes passa desapercebido o quão estamos sedentes de carinhos, o quão as nossas crianças estáo implorando por um tempo afetivo, por um tempo de olharmos para elas e ver que apenas são crianças, crianças querendo ser crianças.

Precisamos respeitar o tempo da criança, desacelerar, estar junto, olhar na mesma direção e da mesma altura, escutar e entrar num tempo onde a calma abre espaço para a imaginação, a base da vida não é só o amor, mas também o respeito, pois só existe amor quando existe respeito.

Como afirma Freire (1986, p. 11) “É na fala do educador, no ensinar (intervir, desenvolver, encaminhar), expressão do seu desejo, casado com o desejo que foi lido, compreendido pelo educando, que lhe tece seu ensinar. Ensinar e aprender são movidos pelo desejo e pela paixão". Um professor afetivo tendo como seu elemento de trabalho a afetividade diária em sala de aula, contribui muito na construção da afetividade dos seus alunos tornando - o capaz de construir laços afetivos com o mundo.

Aprendemos aquilo que nos faz sentido e o aluno precisa entender o sentido de um determinado conhecimento para a sua vida, para que possa aprender. Para a psicopedagogia o aprendizado de um aluno acontece entre o cognitivo e o afetivo. Apesar de sua premência e importância, ainda não se consegue estabelecer um corpo, consistente de açóes educativas no tocante a questão da relação cognição e afetividade. Ademais, sabemos que o sentido de aprendizagem é único e particular na vida de cada um, e que inúmeros são os fatores afetivos e emocionais, que podem impedir o investimento energético necessário ás aquisições escolares. (BOSSA, 1994).

\section{Mediação pedagógica/ psicopedagógica}

O papel do psicopedagogo é relevante no diagnóstico e tratamento, bastante presente nas salas de aulas. Cabe a intervenção educativa em diversas dimensóes como afetiva, cognitiva, orgânica e psicossocial tendo como avaliação psicopedagógico, sendo como o papel central do diagnóstico da criança com TDAH.

Como já salientado anteriormente o TDAH apresenta três principais sintomas, distração, hiperatividade e impulsividade e o primeiro passo para o auxílio deste diagnostico é observar algumas dicas que seguem a seguir:

Por objetivo compreender, estudar e pesquisar a aprendizagem nos aspectos relacionados com o desenvolvimento e ou problemas de aprendizagem. A aprendizagem é entidade aqui como decorrente de uma construção, de um 
processo que implica em questionamentos, hipóteses, reformulaçôes, enfim, implica em dinamismo. A psicopedagogia tem como meta compreender a complexidade dos múltiplos fatores envolvidos neste processo. (RUBINSTEIN apud SCOZ, 2003 p. 127).

Entende - se que quanto mais cedo o diagnostico for realizado, mais cedo será feito as intervençóes necessárias, e maior será a chance de a criança não desenvolver sintomas secundários, progredindo assim no âmbito escolar social e afetivo.

O principal instrumento de avaliação de um psicólogo ou de outro profissional habilitado que queira avaliar a possibilidade do TDAH, é puramente a observação, uma observação muito especial. O psicopedagogo tem que ter em mente que cada pessoa é única e cada qual tem a sua história de vida.

O trabalho da psicopedagogia tem uma grande importância e uma grande demanda para o desenvolvimento de uma educaçáo significativa com um grande significado para o aluno e para o educador.

Piaget (1981 apud Bazi e Sisto, 2008), já considerava a importância dos aspectos cognitivos e afetivos na construção do conhecimento, mostrando que elementos cognitivos se encontram em estados afetivos, atuando como papel fundamental nos sentimentos sendo eles elementares ou mais elaborados. Por tanto o processo de aprendizagem não pode se dissociar da afetividade, já que ela é a fonte de energia para o funcionamento da inteligência.

A relação da afetividade é contemplada com cargas positivas, marcando a aquisição do conhecimento, contribuindo para a autonomia e na confiança de tomada de decisóes. Compreender o mundo real através do pensar, sentir imaginar e agir, fundamenta para estar em campo real.

Refletir este processo:

É compreender que a vida afetiva - emoçóes e sentimentos - compóe o homem e constitui um aspecto de fundamental importância na vida psíquica. As emoções e sentimentos são como alimentos de nosso psíquico e estão presentes em todas as manifestaçóes de nossa vida. Necessitamos deles porquê [...] orientam - nós e nos ajudam nas decisōes (BOCK; FURTADO; TEIXEIRA, 2008, p. 198).

As crianças com TDAH, aparentemente apresentam os sintomas de Déficit de atenção, hiperatividade e impulsividade, mas ao mesmo tempo são crianças que esperam muita afetividade e elogios, pois sempre que podem buscam um colinho e um carinho, sem deixar de ressaltar daqueles abraços gostosos e apertados.

As vezes mal se imagina o que pode passar a representar um simples gesto de um educador. $\mathrm{O}$ que pode um gesto aparentemente insignificante valer como força formadora ou como contribuição à do educando por si mesmo (FREIRE, 1987, p. 47).

Para Cury (2003, p. 97), a educação do afeto deve ser a meta de todo o educador; os educadores que não provocam a emoção das crianças não educam apenas informam, assim como dar conselhos e orientaçóes sem emoção não gera momentos educacionais.

Se observa então que pare ter sucesso como educador e fazer a diferença, é preciso muito mais que entender é preciso desenvolver o papel em torno do cuidado, do acolhimento, da alegria e do afeto. Ter paciência mesmo em situaçôes difíceis mostra o que realmente um TDAH precisa. É preciso controlar suas ansiedades para que a criança controle seus conflitos. Para Freire 
(1987, p. 76), "o professor irresponsável, o professor amoroso da vida da gente, o professor malamado, sempre com raiva do mundo e das pessoas, frio, burocrático, racionalista, nenhum deles vai passar pelos seus alunos sem deixar a sua marca".

O educador através da mediação, da afetividade e da capacidade psicológica de tentar entender os sentimentos e emoçóes das crianças, irá conseguir passar os seus conhecimentos, pois a marca na vida da criança será o que foi feito com amor, carinho, atenção e afeto, e não o que feito com ódio e raiva. Entretanto fica claro que a mediação precisa andar de braços dado com afetividade, pois e neste conjunto de atuação que se alcançará a melhor conquista com o real objetivo.

\section{Consideraçóes finais}

Diante do estudo feito sobre a importância do mediar e da afetividade, podemos observar que estes processos tem uma função primordial e muito significativa no aprendizado do aluno com TDAH. Ressaltando que é através do mediar com afetividade que o educador irá conquistar seu aluno e terá um grande sucesso no bom aproveitamento de seu desenvolvimento educacional.

Salientando que toda criança com TDAH é capaz de aprender, basta apenas dar - lhe tempo, dedicação, afeto e persistência, basta apenas que seja compreendida para ter um bom desempenho, sentindo assim segura para expor suas aflições.

\section{Referências}

BARKLEY, R. A. Transtorno de déficit de atençáo/hiperatividade (TDAH): guia completo para pais, professores e profissionais da saúde. Porto Alegre: Artmed, 2002.

BAZI, G. A.; SISTO, F. F. P. Alegria, tristeza, medo e coragem em crianças com dificuldades de aprendizagem. In: SISTO, F. F.; MARTINELLI, S. de C. Afetividade e dificuldades de aprendizagem: uma abordagem psicopedagógica. São Paulo: Vetor, 2008.

BOCK, A. M. B.; FURTADO, O.; TEIXEIRA, M. L. T. Psicologias: uma introdução ao estudo da psicologia. 14a ed. Sáo Paulo: Saraiva, 2008.

BOSSA, N. A Psicopedagogia no Brasil: contribuições a partir da prática. Porto Alegre: Artes Médicas Sul, 1994.

CURY, A. J. Pais brilhantes, professores fascinantes. Rio de Janeiro: Sextante, 2003.

FREIRE, P. Pedagogia do Oprimido. 10. ed. Rio de Janeiro: Paz e Terra, 1987.

LIMA, J. dos S; SOUSA, R. L. M.; A prática docente e a questão da afetividade na relação professor-aluno. Revista Ágora, Salgueiro/PE, v. 3, n. 1, p. 06 - 16, 2008. Disponível em: <http://www.iseseduca.com.br/pdf/revista3/arquivo33.pdf>. Acesso em: 02 out 2020.

MAHONEY, Abigail Alvarenga. Introdução. In: MAHONEY, Abigail Alvarenga; ALMEIDA, Laurinda Ramalho. Henri Wallon: psicologia e educação, São Paulo: Loyola. 2000.

ROHDE, L. A. P.; MATTOS, P. Princípios e práticas em TDAH. Porto Alegre: Artmed, 2003. 
ROSSINI, M. A. S. Pedagogia Afetiva. 4. ed. Petrópolis, RJ: Vozes, 2001.

SALTINI, Claudio J. P. Afetividade e Inteligência. Rio de Janeiro: Wak, 2008.

SCOZ, B. et al. Psicopedagogia: contribuição para a educação pós-moderna. Petrópolis, RJ: Vozes; São Paulo: ABPp, 2003.

SOLÉ, Isabel. Estratégias de Leitura. Trad. Cláudia Schilling. 6. ed. Porto Alegre: Art Méd, 1998.

VIGOSTKI, L. S. Teoria e Método em Psicologia. São Paulo: Martins Fontes, 2004.

WALLON, H. Afetividade e aprendizagem: Contribuiçôes de Henry Wallon. São Paulo: Ediçôes Loyola, 2007. 